\title{
Factors relating to the development of hypertension after cardiopulmonary bypass
}

\author{
TIMOTHY J COOPER, ^ THOMAS H CLUTTON-BROCK, SIMON N JONES, \\ JACK TINKER, TOM TREASURE
}

\section{From the Intensive Therapy Unit and the Department of Cardiothoracic Surgery, Middlesex Hospital, London}

SUMmary Paroxysmal hypertension after cardiac surgery is a phenomenon of physiological and clinical significance. The possible preoperative and intraoperative factors that may predict its occurrence were studied in 81 consecutive patients undergoing coronary artery surgery $(n=58)$ or valve replacement $(n=27)$, of whom $45(56 \%)$ developed postoperative hypertension. Hypertension occurred significantly more often in those patients who received beta adrenergic blocking agents preoperatively and who underwent coronary artery surgery. Patients with hypertension had significantly higher mean left ventricular ejection fractions preoperatively (52\%) than those without (41\%) and required phentolamine significantly more often and isoprenaline significantly less often intraoperatively.

It is suggested that the significance of preoperative beta adrenergic blockade, the type of operation, and the intraoperative requirement for phentolamine in patients who developed postoperative hypertension may indicate the role of enhanced sympathetic activity and disturbance of cardiac receptors during surgery. Preoperative myocardial performance and the method of myocardial protection during surgery are likely to influence the occurrence of the hypertensive phenomenon.

Early postoperative hypertension complicating coronary artery surgery is well recognised with a reported incidence of $30-60 \% .^{1-3}$ The hypertensive episode usually develops within an hour of cardiopulmonary bypass, is well established by the time the patient returns to the intensive care unit, and if untreated persists despite adequate analgesia for 6-8 hours. The associated hazards are considerable, including increase in myocardial oxygen consumption, cerebrovascular accidents, and the risk of suture line disruption. Haemodynamic studies show that hypertension after cardiopulmonary bypass is due to increased systemic vascular resistance with practically unaltered cardiac output, ${ }^{34}$ and that cardiac reflexes, ${ }^{5}$ the sympathetic nervous system, ${ }^{3}$ the renin-angiotensin axis, ${ }^{6}$ and vasopressin ${ }^{7}$ may be implicated in this peripheral vasoconstriction. The hypertension responds to vasodilator agents, but a fuller understanding of its cause

Requests for reprints to $\mathrm{Mr} \mathrm{T}$ Treasure, Department of Cardiothoracic Surgery, The Middlesex Hospital, Mortimer Street, London WIN 8AA.

*Present address: Department of Medicine, Southmead Hospital, Westbury on Trym, Bristol BS10.

Accepted for publication 11 March 1984 may depend on identification of predisposing factors. The purpose of this study was to determine whether certain preoperative and intraoperative factors are predictive of hypertension after cardiopulmonary bypass.

\section{Patients and methods}

Eighty one consecutive patients (69 men and 12 women) scheduled for coronary artery surgery or valve replacement were studied prospectively over a three month period in 1983. Of these, 54 patients underwent coronary artery surgery, 23 valve replacement, and four both.

A past history of hypertension was noted, and current medications including beta adrenergic blocking agents and nifedipine were continued preoperatively. These medications were given until 6-10 hours before operation. In 39 patients the left ventricular ejection fraction was determined preoperatively by radionuclide gated acquisition scan.

SURGICAL PROCEDURE

All patients received diazepam $(10 \mathrm{mg})$ two hours 
Table 1 Preoperative clinical characteristics and intraoperative variables in patients with and without hypertension after cardiopubmonary bypass

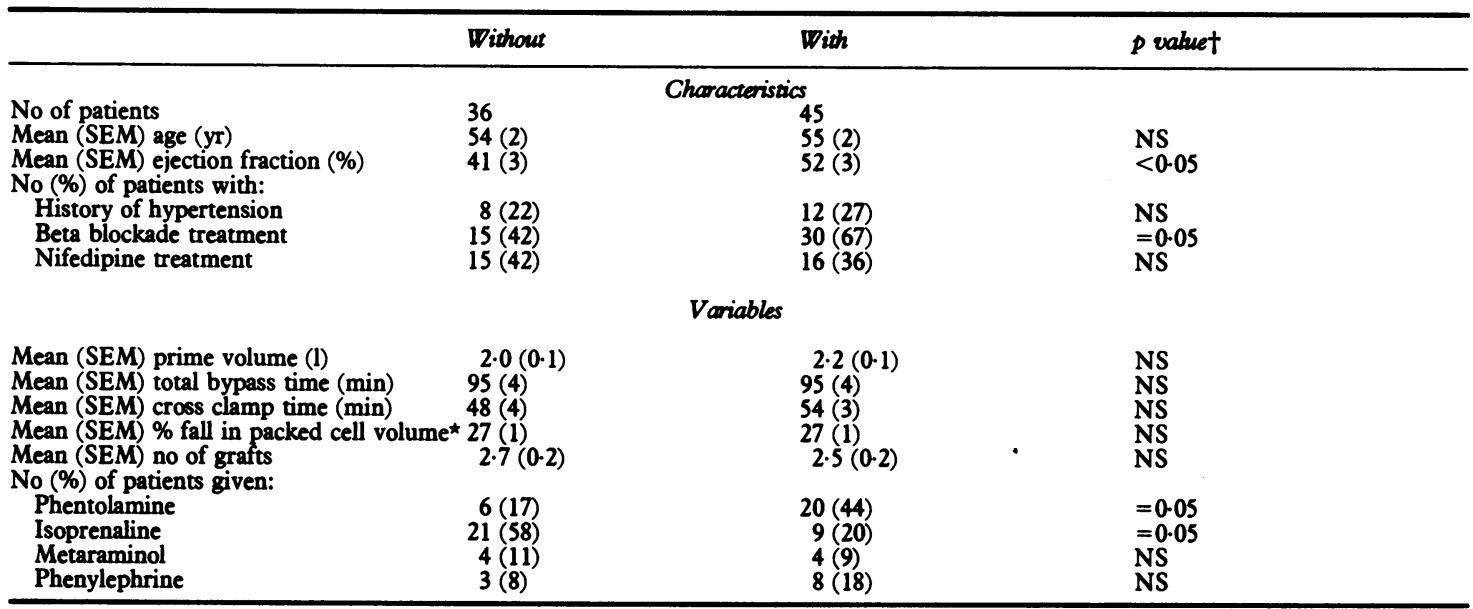

*Percentage fall in preoperative packed cell volume at onset of cardiopulmonary bypass.

tFisher's exact test (two tail) or Student's $t$ test.

preoperatively with papavaretum $(0.3 \mathrm{mg} / \mathrm{kg})$ and scopolamine $(0.4 \mathrm{mg})$ as premedication. Anaesthetic induction was with thiopentone $(2-5 \mathrm{mg} / \mathrm{kg})$, papavaretum $(0.3 \mathrm{mg} / \mathrm{kg})$, and pancuronium $(0.15$ $\mathrm{mg} / \mathrm{kg}$ ). Subsequent anaesthesia was maintained with $50 \%$ nitrous oxide and oxygen, intravenous boluses of papavaretum and lorazepam, or alphaxalonealphadolone acetate by infusion. Radial artery and internal jugular catheters were inserted after induction of anaesthesia. During cardiopulmonary bypass metaraminol $(0.5-1 \mathrm{mg})$ or phenylephrine $(0.2-1 \mathrm{mg})$ were given if perfusion pressure was persistently below $50 \mathrm{~mm} \mathrm{Hg}$ at a pump flow of $2.4 \mathrm{l} / \mathrm{min}$ per $\mathrm{m}^{2}$. Rises in systemic pressure in the latter phase of bypass were controlled by intravenous boluses of phentolamine (1-5 mg). After bypass isoprenaline was given if systolic pressure fell below $80 \mathrm{~mm} \mathrm{Hg}$.

Two surgeons and one perfusionist were involved throughout the study, and pulsatile cardiopulmonary bypass was achieved in all cases with Stockert or Gambro roller pumps and a Bentley SpiraFlo oxygenator. The bypass pump was primed with a measured volume of Hartmann's sodium lactate solution. Moderate systemic hypothermia $\left(27-31^{\circ} \mathrm{C}\right)$ was used with intermittent introduction of cold hyperkalaemic cardioplegia solution into the aortic root and topical cold saline into the pericardial sac. Arterial blood gases, electrolyte concentrations, and packed cell volume were measured at hourly intervals. Table 1 gives the preoperative and intraoperative variables recorded for analysis.

POSTOPERATIVE PROCEDURE

On transfer to the intensive care unit all patients were ventilated to normocarbia. Regular arterial blood sampling and continuous arterial and central venous pressure monitoring were performed. Central venous pressure was maintained with transfusion of blood or plasma at a predetermined level assessed intraoperatively. A bolus dose of papavaretum (10 $\mathrm{mg}$ intravenously) was given within 10 minutes of return to the intensive care unit provided that systolic blood pressue was $>90 \mathrm{~mm} \mathrm{Hg}$. If systolic pressure was persistently $>140 \mathrm{~mm} \mathrm{Hg}$ over the next 10 minutes sodium nitroprusside was infused at an initial rate of $1 \mu \mathrm{g} / \mathrm{kg} /$ $\mathrm{min}$. The infusion rate of nitroprusside was adjusted to maintain systolic pressure at $140 \mathrm{~mm} \mathrm{Hg}$. The total dose of nitroprusside given was recorded.

\section{STATISTICAL ANALYSIS}

Statistical analysis of data was performed using Fisher's exact test (two tail) or Student's $t$ test for unpaired data. Data are expressed either as percentages or as mean values (standard error of the mean).

\section{Results}

Of the 81 patients, 45 (56\%) fulfilled the criteria for hypotensive treatment according to the study protocol, with mean systolic and diastolic blood pressure at 10 minutes after sedation of 158 (3) and 95 (2) $\mathrm{mm}$ Hg. Hypertension was significantly more likely to occur after coronary artery surgery than after valve replacement (37/58 patients os 10/27, $p=0.05$ ) (Table 2).

An analysis of preoperative data showed no significant difference between the postoperatively hypertensive and normotensive patients with regard 
Table 2 Characteristics relating to development of hypertension including mean dose requirement of sodium nitroprusside after cardiopulmonary bypass

\begin{tabular}{|c|c|c|c|c|c|c|}
\hline & \multicolumn{2}{|c|}{$\begin{array}{l}\text { Mean }(S E M) \text { blood pressure } \\
\text { (mm Hg) }\end{array}$} & \multirow{2}{*}{\multicolumn{2}{|c|}{$\begin{array}{l}\text { Patients with } \\
\text { postoperative } \\
\text { hypertension }\end{array}$}} & \multirow{3}{*}{$\begin{array}{l}\text { Mean (SEM) } \\
\text { ejection fraction } \\
\text { (\%) }\end{array}$} & \multirow{3}{*}{$\begin{array}{l}\text { Total dose of } \\
\text { sodivm nitroprusside } \\
\text { (mg/kg) }\end{array}$} \\
\hline & \multirow{2}{*}{ Systolic } & \multirow{2}{*}{ Diastolic } & & & & \\
\hline & & & No & $\%$ & & \\
\hline $\begin{array}{l}\text { Patients with hypertension } \\
\text { Patients without hypertension } \\
\text { Type of surgery: }\end{array}$ & $\begin{array}{l}158(3) \\
120(3)\end{array}$ & $\begin{array}{l}95(2) \\
75(2)\end{array}$ & & & & \\
\hline $\begin{array}{l}\text { Coronary artery bypass graft } \\
\text { Valve replacement } \\
\text { Beta adrenergic blockade: }\end{array}$ & & & $\begin{array}{l}37 \\
10\end{array}$ & $\begin{array}{l}64^{\star} \\
37^{\star}\end{array}$ & $\begin{array}{l}47(3) \\
44(6)\end{array}$ & $\begin{array}{l}1.56(0.32) \\
2.67(0.9)\end{array}$ \\
\hline $\begin{array}{l}\text { Present } \\
\text { Absent } \\
\text { Preoperative hypertension: }\end{array}$ & & & & & & $\begin{array}{l}1.59(0.33) \\
2.34(0.64)\end{array}$ \\
\hline $\begin{array}{l}\text { Present } \\
\text { Absent }\end{array}$ & & & & & & $\begin{array}{l}2.43(0.86) \\
1.65(0.3)\end{array}$ \\
\hline
\end{tabular}

${ }^{\star} \mathrm{p}=0.05$.

to age, history of hypertension, or nifedipine treatment (Table 1). Preoperative beta adrenergic blockade, however, was associated with a significantly higher incidence of hypertension after cardiopulmonary bypass $(p=0.05)$. The left ventricular ejection fraction, assessed preoperatively in 39 patients by gated acquisition scan, was significantly lower in those who remained normotensive postoperatively $(n=19)$ than in the 20 patients who developed hypertension $(p<0.05)$. The preoperative ejection fraction did not differ significantly between patients undergoing coronary artery surgery or valve replacement (Table 2).

Hypertensive and non-hypertensive groups were compared for prime volume, total bypass time, cross clamp time, percentage fall in packed cell volume at the onset of cardiopulmonary bypass, and number of coronary arteries grafted. No significant correlation was observed for the development of hypertension with any of these factors (Table 1). The administration of phentolamiñe during surgery was more common in patients who became hypertensive postoperatively $(p=0.05)$, whereas isoprenaline was used more frequently in patients who did not become hypertensive $(p<0.05)$. Other intraoperative treatments did not differ between the two groups.

In the hypertensive group the total dose of sodium nitroprusside required to control the hypertensive episode tended to be larger in those patients who had a past history of hypertension, who did not have preoperative beta adrenergic blockade, and in those who had undergone valve surgery (Table 2 ). These observations, however, did not reach statistical significance.

\section{Discussion}

The mechanisms of hypertension after cardiopulmonary bypass have been inconclusively investigated.
Increased systemic vascular resistance with normal cardiac output is characteristic of the haemodynamic profile. ${ }^{489}$ It is known that certain cardiac reflexes, ${ }^{10}$ the sympathoadrenal system, and the reninangiotensin axis can cause pronounced peripheral vasoconstriction. In some studies of coronary artery surgery, postoperative hypertension has been associated with the severity of coronary artery disease, ${ }^{38}$ normality of preoperative angiography, ${ }^{8}$ preoperative beta adrenergic blockade, ${ }^{11}$ history of hypertension, ${ }^{3}$ and the number of vein grafts. ${ }^{8}$ The latter two factors were not found to be of importance in this study. An important finding was the lower incidence of hypertension after valve surgery.

Patients who did not become hypertensive postoperatively had a significantly lower ejection fraction preoperatively than hypertensive patients $(p<0.05)$. Furthermore, the non-hypertensive patients had a significantly greater requirement for isoprenaline after cardiopulmonary bypass $(p<0.05)$. In a study of 28 patients undergoing coronary artery surgery hypertension was reported to occur more often in patients with normal preoperative angiography. ${ }^{8}$ These findings suggest that preoperative myocardial performance is critical to the development of postoperative hypertension, provided that myocardial protection during surgery is adequate. A lower incidence of hypertension in previous reports 1312 may represent either poorer preoperative myocardial performance or poorer methods of myocardial protection. Moderate systemic hypothermia with intermittent introduction of cold cardioplegia preserves myocardial performance, ${ }^{13}$ affording better protection than either hypothermic ischaemic arrest, intermittent anoxic arrest, or single dose cardioplegia.

The difference in incidence of hypertension according to the type of operation may be related to sympathetic reflexes originating from the heart, great ves- 
sels, or coronary arteries. Cardiac reflexes with spinal sympathetic afferent input that are predominantly pressor in nature have been identified. ${ }^{14}$ Efferent sympathetic activity producing peripheral vasoconstriction is further observed in the cardiogenic hypertensive chemoreflex ${ }^{10}$ in response to stimulation of chemoreceptors in the vicinity of the left coronary artery. Surgical interference with the heart, great vessels, and coronary arteries may stimulate the reflexes, particularly during coronary artery surgery.

In favour of a reflex mechanism for hypertension after cardiopulmonary bypass is the paroxysmal nature of the hypertension and the temporal relation of increasing systemic vascular resistance with cardiac manipulation. Systemic vascular resistance increases in parallel with rises in plasma noradrenaline concentration during bypass ${ }^{9}$ and aortic cross clamping, ${ }^{15}$ and both rise to a significantly greater extent in patients who become hypertensive postoperatively. ${ }^{8}$ The major fraction of circulating noradrenaline is derived from innervation of vascular smooth muscle. ${ }^{16}$ In our study patients who became hypertensive postoperatively required phentolamine, an alpha adrenergic antagonist, significantly more often during bypass $(p=0.05)$, presumably because of increasing systemic vascular resistance. A profound sympathetic stimulus in the heart during bypass is further suggested by the observation that coronary sinus blood contains a higher concentration of noradrenaline that arterial blood immediately after cardiac reperfusion. ${ }^{15}$

The sympathetic nervous system may be stimulated by a variety of other influences in the perioperative period including hypothermia, ${ }^{17}$ hypotension, alterations in the flow pattern, ${ }^{18}$ and haemodilution. ${ }^{19}$ Haemodilution may reduce the depth of intravenous anaesthesia on bypass and reduces blood viscosity. ${ }^{19}$ Hypertensive and non-hypertensive patients cannot, however, be differentiated on the basis of hypothermia within the small range of operating temperatures in this study. Furthermore, the lack of correlation with total bypass time, volume of prime, and fall in packed cell volume mitigates against the putative contribution of flow changes, hypotension, and haemodilution in influencing systemic vascular resistance.

Patients who received preoperative beta adrenergic blockade were significantly more likely to develop hypertension after cardiopulmonary bypass $(p=0.05)$. In the presence of persistent beta adrenergic blockade, adrenergic stimulation may result in unopposed alpha adrenergic activity. The response of peripheral vasodilatation mediated by beta adrenergic receptors is blocked and peripheral vasoconstriction is likely. After withdrawal of propranolol serum and tissue concentrations take at least $\mathbf{4 8}$ hours to fall sufficiently to allow a normal response to pharmacological beta adrenergic stimulation. ${ }^{2021}$ In a study in which 14 of 15 patients receiving propranolol before coronary artery surgery became hypertensive, a significant correlation was found between postoperative serum propranolol concentrations and dose requirement for sodium nitroprusside. ${ }^{11}$ In the present study, hypertensive patients who received preoperative beta adrenergic blockade tended to require a higher total dose of nitroprusside, although the difference was not significant.

The renin-angiotensin axis is activated by nonpulsatile renal perfusion, ${ }^{22}$ but evidence for its activation during cardiopulmonary bypass is conflicting. 92324 Renin may initiate hypertension through formation of angiotensin II, which is a potent pressor agent, or it may potentiate the vasoconstrictor effect of catecholamines in sustaining hypertension. ${ }^{25}$ Renin secretion is known to occur in response to sympathetic stimulation, mediated by beta adrenergic receptors. ${ }^{26}$ Plasma renin activity is depressed during beta adrenergic blockade and remains so for 12 hours after withdrawal of the drug. ${ }^{27}$ Subsequent values for plasma renin activity show a rebound rise persisting for more than 72 hours in conjunction with a nonsignificant rise in blood pressure. ${ }^{27}$ It is not surprising that the role of the renin-angiotensin axis in hypertension after cardiopulmonary bypass hypertension is confused and probably diminished in circumstances of persistent beta adrenergic blockade.

A possible mechanism for hypertension after cardiopulmonary bypass is that of disturbance of cardiac receptors causing increased sympathetic nervous system tone. This is more likely to result in increased systemic vascular resistance in the presence of persistent beta adrenergic blockade. Further study is needed to identify critical surgical influences that trigger cardiac reflexes. An analysis of preoperative data indicates that myocardial performance is contributory to the hypertension. An increased incidence of the hypertensive phenomenon may represent improved myocardial protection during cardiopulmonary bypass.

\section{References}

1 Estafanous FG, Tarazi RC, Viljoen JF, El Tawil MY. Systemic hypertension following myocardial revascularization. Am Heart f 1973; 85: 732-8.

2 Hoar PF, Hickey RF, Ullyot DJ. Systemic hypertension following myocardial revascularization: a method of treatment using epidural anesthesia. $\mathcal{F}$ Thorac Cardiovasc Surg 1976; 71: 859-64.

3 Roberts AJ, Niarchos AP, Subramanian VA, et al. Systemic hypertension associated with coronary artery bypass surgery: predisposing factors, hemodynamic characteristics, humoral profile, and treatment. $\mathcal{f}$ Thorac Cardiovasc Surg 1977; 74: 846-59. 
4 Estafanous FG, Urzua J, Yared JP, Zurick AM, Loop FD, Tarazi RC. Pattern of hemodynamic alterations during coronary artery operations. $\mathcal{F}$ Thorac Cardiovasc Surg 1984; 87: 175-82.

5 Fouad FM, Estafanous FG, Bravo EL, Iyer KA, Maydak JH, Tarazi RC. Possible role of cardioaortic reflexes in postcoronary bypass hypertension. Am $\mathcal{F}$ Cardiol 1979; 44: 866-72.

6 Taylor KM, Morton IJ, Brown JJ, Bain WH, Caves PK. Hypertension and the renin-angiotensin system following open-heart surgery. F Thorac Cardiovasc Surg 1977; 74: 840-5.

7 Hawkins SS, Aveling W, Treasure T, Forsling M. Hypertension, vasopressin and renin in coronary artery surgery. $\mathrm{Br} \mathcal{F}$ Anaesth 1983; 55: 1161P.

8 Wallach R, Karp RB, Reves JG, Oparil S, Smith LR, James TN. Pathogenesis of paroxysmal hypertension developing during and after coronary bypass surgery: a study of hemodynamic and humoral factors. Am $\mathcal{Y}$ Cardiol 1980; 46: 559-65.

9 Hoar PF, Stone JG, Faltas AN, Bendixen HH, Head RJ, Berkowitz BA. Hemodynamic and adrenergic responses to anesthesia and operation of myocardial revascularization. F Thorac Cardiovasc Surg 1980; 80: 242-8.

10 James TN, Hageman GR, Urthaler F. Anatomic and physiologic considerations of a cardiogenic hypertensive chemoreflex. Am f Cardiol 1979; 44: 852-9.

11 Bolling SF, Flaherty JT, Porter AM, Gardener TJ. Propranolol-induced postoperative hypertension following coronary artery bypass grafting. F Thorac Cardiovasc Surg 1984; 87: 112-9.

12 Estafanous FG, Tarazi RC, Buckley S, Taylor PC. Arterial hypertension in immediate postoperative period after valve replacement. Br Heart $\mathcal{f}$ 1978; 40: 718-24.

13 Fremes SE, Weisel RD, Baird RJ, et al. Effects of postoperative hypertension and its treatment. $\mathcal{F}$ Thorac Cardiovasc Surg 1983; 86: 47-56.

14 Brown AM. Coronary pressor reflexes. Am $\mathcal{f}$ Cardiol 1979; 44: 849-51.

15 Reves JG, Karp RB, Buttner EE, et al. Neuronal and adrenomedullary catecholamine release in response to cardiopulmonary bypass in man. Circulation 1982; 66: 49-55.

16 Kopin IJ, Lake RC, Ziegler M. Plasma levels of norepinephrine. Ann Intern Med 1978; 88: 671-80.

17 Arnett EL, Watts DT. Catecholamine excretion in men exposed to cold. F Appl Physiol 1960; 15: 499-500.

18 Hine IP, Wood WG, Mainwaring-Burton RW, Butler $M J$, Irving $M H$, Booker B. The adrenergic response to surgery involving cardiopulmonary bypass, as measured by plasma and urinary catecholamine concentrations. $\mathrm{Br}$ f Anaesth 1976; 48: 355-63.

19 Replogle R, Levy M, DeWall RA, Lillehei RC. Catecholamine and serotonin response to cardiopulmonary bypass. F Thorac Cardiovasc Surg 1962; 44: 638-48.

20 Romagnoli A, Keats AS. Plasma and atrial propranolol after preoperative withdrawal. Circulation 1975; 52: 1123-7.

21 Faulkner SL, Hopkins JT, Boerth RC, et al. Time required for complete recovery from chronic propranolol therapy. N Engl f Med 1973; 289: 607-9.

22 Many M, Giron F, Birtwell WC, Deterling RA Jr, Soroff HS. Effects of depulsation of renal blood flow upon renal function and renin secretion. Surgery 1969; 66: 242-9.

23 Salerno TA, Henderson M, Keith FM, Charrette EJP. Hypertension after coronary operation: can it be prevented by pulsatile perfusion. $\mathcal{F}$ Thorac Cardiovasc Surg 1981; 81: 396-9.

24 Taylor KM, Bain WH, Russell M, Brannan JJ, Morton IJ. Peripheral vascular resistance and angiotensin II levels during pulsatile and non-pulsatile cardiopulmonary bypass. Thorax 1979; 34: 594-8.

25 Peach MJ, Cline WH Jr, Watts DT. Release of adrenal catecholamines by angiotensin. Circ Res 1966; 19: 571-5.

26 Michelakis AM, Horton R. The relationship between plasma renin and aldosterone in man. Circ Res 1970; 27 (suppl I): 185-94.

27 Garrett BN, Kaplan NM. Plasma renin activity suppression: duration after withdrawal from beta-adrenergic blockade. Arch Intern Med 1980; 140: 1316-8. 